\title{
Cholecystectomy for Complicated Gallbladder and Common Biliary Duct Stones: Current Surgical Management
}

OPEN ACCESS

Edited by:

Vincenzo Neri,

University of Foggia, Italy

Reviewed by:

Gabriel Sandblom,

Karolinska Institutet (KI), Sweden Marcello Picchio,

Azienda Sanitaria Locale Roma 6, Italy

*Correspondence:

Louis J. Koizia

I.koizia@nhs.net

Specialty section:

This article was submitted to Visceral Surgery,

a section of the journal

Frontiers in Surgery

Received: 25 April 2020

Accepted: 08 June 2020

Published: 21 July 2020

Citation:

Argiriov Y, Dani $M$, Tsironis $C$ and Koizia LJ (2020) Cholecystectomy for

Complicated Gallbladder and Common Biliary Duct Stones: Current

Surgical Management.

Front. Surg. 7:42

doi: $10.3389 /$ fsurg.2020.00042

\author{
Yanna Argiriov ${ }^{1}$, Melanie Dani ${ }^{1}$, Christos Tsironis ${ }^{2}$ and Louis J. Koizia ${ }^{1 *}$ \\ ${ }^{1}$ Cutrale Perioperative and Ageing Research Group, Department of Bioengineering, Imperial College London, London, \\ United Kingdom, ${ }^{2}$ Department of Surgery, Imperial College Healthcare NHS Trust, London, United Kingdom
}

Gallstone disease accounts for the vast majority of acute surgical admissions in the UK, with a major treatment being cholecystectomy. Practice varies significantly as to whether surgery is performed during the acute symptomatic phase, or after a period of recovery. Differences in practice relate to operative factors, patient factors, surgeon factors and hospital and trust wide policies. In this review we summarize recent evidence on management of gallstone disease, particularly with respect to whether cholecystectomy should occur during index presentation or following recovery. We highlight morbidity and mortality studies, cost, and patient reported outcomes. We speculate on barriers to change in service delivery. Finally, we propose potential solutions to optimize care.

Keywords: cholecystectomy, early cholecystectomy, delayed cholecystectomy, gallstones, biliary disease

\section{INTRODUCTION AND OBJECTIVES}

Gallstone-related disease was the commonest cause of hospital admissions in the developed world at the beginning of the 21st Century $(1,2)$. In developed nations, gallstones affect $10-20 \%$ of adults (3-5), of whom $80 \%$ are asymptomatic $(5,6)$. The remainder can present with anything from biliary colic, cholecystitis, cholangitis, choledocholithiasis (i.e., common bile duct [CBD] stones) and gallstone pancreatitis (7-11), to rarer severe variants such as Mirizzi's syndrome, gangrenous, haemorrhagic, or emphysematous cholecystitis. The latter group tend to have non-specific clinical, serological and radiological findings which can make diagnosis difficult (12-25).

Tokyo Guidelines 2018 (TG18) acknowledge that gallstone disease can present diversely and non-traditionally and outline various workup and management strategies according to patients' comorbidities, presentation, biomarkers, diagnosis and disease severity (26).

Under TG18, three key criteria must be present to diagnose acute cholangitis and acute cholecystitis, respectively (27). For a definite acute cholangitis diagnosis there must be: (1) Leucocytosis $>10 \times 10^{9} / \mathrm{L}$ and CRP $>10 \mathrm{mg} / \mathrm{L}$, and/or fevers/chills, plus (2) Consistent imaging findings (described below), plus (3) signs of cholestasis. This can be jaundice/ bilirubin $>20 \mathrm{mg} / \mathrm{L}$ or deranged liver function tests (LFTs): i.e., alkaline phosphatase (ALP), $\gamma$-glutamyl transpeptidase (GGT), alanine aminotransferase (ALT), and aspartate aminotransferase (ALT) at $1.5 \mathrm{x}$ their upper limit of normal (28). GGT in particular has high positive and negative predictive values, with 10x higher probability of CBD stones when GGT $>90$ units/L (29).

For acute cholecystitis, points (1) and (2) are as above (with absence of "chills" in point 1), but the third criterion differs in that jaundice and deranged LFTs are not part of an acute cholecystitis diagnosis. Instead, there must be a mass, pain or tenderness in the right upper quadrant, or a positive Murphy's sign (30). 
Transabdominal ultrasound is the gold-standard imaging for acute cholecystitis and detects over $80 \%$ of cases (31-35). In acute uncomplicated cholecystitis, ultrasound may show gallstones, a positive sonographic Murphy's sign, thickened gallbladder wall, pericholecystic fluid, "sludge" in the gallbladder, gallbladder distension, and hyperaemia of the gallbladder wall on Doppler $(30,36-38)$. However, it is limited in detecting severe variants such as gangrenous or emphysematous cholecystitis or intraabdominal abscess, where CT is more appropriate $(14,24,30,37)$. Cholescintigraphy has shown to be diagnostically superior to ultrasound, with smaller error margins $(39,40)$, but is limited in practice as it can take several hours, irradiates the patient and cannot look beyond the hepatobiliary tract (41). Ultrasound therefore remains recommended by the National Institute for Health and Care Excellence (NICE) (42).

In choledocholithiasis, abdominal ultrasound may detect stones or dilation of the CBD bile duct $(28,33)$, but not consistently. Magnetic Resonance Cholangiopancreatography (MRCP) is more sensitive for CBD abnormalities, and can be used if ultrasound is inconclusive (28). The Association of Upper Gastrointestinal Surgery of Great Britain and Ireland (AUGIS) suggest MRCP only for high-risk patients: i.e., those with CBD $>10 \mathrm{~mm}$ on ultrasound with abnormal LFTs and bilirubin. Even then, cholecystectomy with intra-operative cholangiography (IOC) is preferable (43). Other guidelines also propose MRCP for intermediate-risk patients (although do acknowledge IOC as an alternative) (44-46).

Once identified, CBD stones should be removed within $72 \mathrm{~h}$ if the patient is jaundiced, or within $24 \mathrm{~h}$ for acute cholangitis or pancreatitis (47). This should be by preoperative Endoscopic Retrograde Cholangiopancreatography (ERCP) or intra-operative laparoscopic bile duct exploration plus cholecystectomy (43).

Indeed, laparoscopic cholecystectomy is the gold-standard treatment for symptomatic gallstones $(45,48-51)$. For those with acute cholecystitis, NICE recommends laparoscopic cholecystectomy within 1 week of presentation; within $72 \mathrm{~h}$ is the ideal $(42,52-54)$. Almost 70,000 cholecystectomies are performed each year in the UK (costing more than $£ 110$ million) (55). Despite recommendations, only $15 \%$ of these are done early (i.e., on index admission) $(56,57)$, with patients instead being discharged and operated on electively.

This article will discuss early vs. delayed laparoscopic cholecystectomy, discuss reasons for operating delays, and propose how to mitigate these delays in the UK health service.

\section{WHY EARLY CHOLECYSTECTOMY IS IMPORTANT}

\section{Safety}

In the 1990's, studies suggested early cholecystectomy had higher conversion rates, longer operation times and increased risk of complications (58-61). However, countless studies since proved early procedures are safe $(62,63)$, some of which we will now discuss.
In 2015, Cao et al. published a meta-analysis of 14 randomized control trials involving 1,608 patients showing that morbidity was double in patients undergoing delayed cholecystectomy (30 vs. $15 \%$ ), with higher rates of wound infection. Conversion rates were the same regardless of procedure timing (64), although some studies have found conversion rates significantly lower in early groups $(52,65-68)$.

In older patients, morbidity in delayed procedures is higher still. Cull et al. (69) reviewed 265 cholecystitis patients over 65 years-of-age, and found those undergoing cholecystectomy over 7 days from symptom-onset were four times more likely to develop recurrent biliary tract infection prior to surgery compared to those that had cholecystectomy within 7 days. Two percentage of the delayed cholecystectomy group died, whereas there were no deaths in the early group, although this was not statistically significant (69).

A previous concern of early laparoscopic cholecystectomy was heightened risk of bile duct injury, due to inflammatory adhesions to adjacent structures (70). However, repeated attacks of cholecystitis (as can occur in elective patients) can also result in gallbladder adherence to surrounding structures, making surgery equally problematic $(62,71-73)$.

A large Canadian retrospective cohort study of 22,202 acute cholecystitis patients found early cholecystectomy in fact carries significantly lower probability of major bile duct injury (relative risk 0.53 ) with no statistically significant difference in mortality or conversion rates (74). Recently, even larger studies have supported this finding $(52,75)$.

A meta-analysis of 451 patients by Gurusamy et al. (76) found $17.5 \%$ of interval cholecystectomy patients re-presented and required emergency surgery before their planned date. Of these patients, $45 \%$ required conversion to an open operation, more than double the originally-stated interval group conversion rate. This suggests that conversion and morbidity may be significantly higher in delayed cholecystectomy groups when those requiring emergency interventions are considered. It has even been suggested that delaying cholecystectomy increases risk of severe variants such as gangrenous cholecystitis $(77,78)$.

Early cholecystectomy is also beneficial in acute cholangitis. Discolo et al. (79) compared early and late cholecystectomy in acute cholangitis and found those undergoing delayed procedures were more likely to have post-operative complications, and/or recurrent cholangitis before their surgery. Differences in intra-operative complication rates were negligible. Similarly, delaying cholecystectomy for gallstone pancreatitis patients has also been linked to recurrence and increased complications (80).

\section{Readmissions and Length of Stay}

Increased morbidity in delayed cholecystectomy, as discussed above, is in part due to emergency gallstone-related readmissions whilst awaiting surgery (81), rates of which can be as high as 20$29 \%$ (82-86). For those awaiting cholecystectomy for more than 20 weeks, readmission rates increase threefold (87).

Total length of stay is also longer when cholecystectomy is delayed. Papi et al. (62) showed that delayed cholecystectomy 
patients stayed in hospital an extra 8.2 days on average, compared to the early group.

Some studies show the difference to be smaller (around 2-4 days) $(63,74,85,88-91)$, but all studies looking at length of stay found it shorter for early procedures (52, 64, 76, 84, 92-94), even when comparing open cholecystectomy approaches (95).

\section{Patient Reported Outcomes}

In elective patients, waiting for surgery leads to a prolonged period of impaired health with psycho-social implications for patients.

Oudhoff et al. (96) found patients awaiting cholecystectomy exhibit signs of lethargy and anxiety which are positively correlated to symptomatology, complications and readmission, and improve once the procedure is done. Women awaiting cholecystectomy had higher social dysfunction than women with breast cancer awaiting biopsy (96).

A further qualitative study by Lindseth and Denny (97) featured quotes from patients awaiting cholecystectomy electively; some describing the pain as "excruciating." Patients unanimously described inability "to enjoy eating or follow their usual dietary habits" and some "had significant weight loss... afraid to eat for fear of the pain." Sleep disturbance pre-operatively was also common (97).

\section{Cost}

Repeated gallstone-disease flares increase spend due to repeated admissions and longer average bed stays $(62,84,98)$. A UK study by Jones et al. (88) showed that inpatient bed costs were the second-largest cholecystectomy spend after the operation itself and could reach up to $£ 2849$ per patient. By reducing length of stay, early cholecystectomy could result in significant cost-savings for hospitals.

Various UK-based literature has outlined cost-effectiveness of early procedures for acute cholecystitis. Wilson et al. (99) found early procedures were overall $£ 820$ cheaper per patient and could save the NHS $£ 821,540$ for every thousand patients treated, totalling $£ 8.5$ million savings per annum. Early cholecystectomy patients also scored better on Quality-Adjusted Life Year (QALY) criteria (early: $£ 2,574,457$ per 1,000 patients, QALYs 876.48. Delayed: $£ 3,395,997$ per 1,000 patients, QALYs 825.05$)$ with a hospital stay 4.12 days shorter (99).

More recent UK economic evaluation by Kerwat et al. (100) found early laparoscopy was on average $£ 645$ cheaper per patient and could save the NHS $£ 27$ million per annum if implemented as standard practice. The discrepancy between estimated NHS savings between studies is likely due to differences in NHS reference costings when the studies were published (2018 vs. 2010).

Morris et al. (101) looked at cost in gallstone pancreatitis patients and found the longer the procedure was postponed, the higher the cost. And even if index admission procedures are done after $72 \mathrm{~h}$, they are still cheaper than discharging patients for interval cholecystectomy (101).

A costing statement by NICE also states that early cholecystectomy could save money from reduced A\&E visits and fewer prescriptions for analgesia and antibiotics
(55). Moreover, NHS tariff prices are considerably higher for emergency laparoscopic cholecystectomy patients than for delayed ones. According to NHS planning prices 2019/20, trusts are paid $£ 3606$ for a "hot" laparoscopic cholecystectomy, vs. $£ 1855$ for an elective one. In complex and comorbid patients, emergency tariff payment can be as high as $£ 6333$ (102). So not only do early procedures save money in terms of bed stay and treatment, they also generate more tariff income.

When considering cost, lost workdays should also be taken into account as this has financial impact on both patients and society as a whole. Gallbladder disease is the most expensive chronic gastrointestinal disorder with regards to lost workdays (103) and socioeconomic cost (104). Early cholecystectomy can reduce lost workdays by up to 11 days $(71,89,105)$.

\section{ISSUES WITH EARLY CHOLECYSTECTOMY}

Early cholecystectomy is not without disadvantages. These will now be discussed.

A meta-analysis of 375 patients by Siddiqui et al. (93) found operating time was 2-45 min longer in early cholecystectomy for acute cholecystitis. Gul et al. (105) found mean operating time 18 min longer in the early cholecystectomy group and $\mathrm{Wu}$ et al. (89) found it 10 min longer. However, multiple other studies have shown negligible or no differences in operation time $(84,85,92,98,106)$. A recent study published in 2019 even showed early procedures to have reduced operation time (107). Differences in early and delayed operation times are also minimal in acute cholangitis (97 vs. 89 min, respectively) (79). Complication and conversion rates were similar regardless of cholecystectomy length.

Although not all studies commented on blood loss, those that did reported early laparoscopic cholecystectomies to have mean extra blood loss of $13-120 \mathrm{ml}$ in early procedures (105, 106, 108-110). This said, other literature does also exist citing differences in blood loss to be insignificant, or even reduced, in early procedures $(111,112)$.

Importantly, it should be noted that early cholecystectomy is not appropriate for all patients, and this is acknowledged in TG18 (113). In those with high comorbidity scores, poor performance statuses, jaundice, cranial neuropathy, respiratory dysfunction, or organ failure that is not rapidly reversible, percutaneous transhepatic gallbladder drainage (PTGD) followed by delayed cholecystectomy at 6 weeks is preferable with better morbidity outcomes (113-115). In these cases, we would not advocate early procedures.

In 2018, Blythe et al. reported that in the "real-world" early cholecystectomy has increased morbidity, mortality and complication rates compared to delayed (116). However, a key issue with the study was that those assigned to the "early" group were already significantly more unwell, had more complex cholecystitis variants (including abscess, empyema, ulceration, necrosis) and higher American Society of Anesthesiologists (ASA) scores: $6.5 \%$ of the early group had a pre-operative ASA 
score of IV, compared to $0 \%$ in the delayed group. Therefore, the results do not accurately reflect daily practice.

\section{REASONS FOR DELAYS}

In 2004, Cameron et al. found only $11 \%$ of surveyed general surgical consultants performed early cholecystectomy for acute cholecystitis. Limiting factors were unavailability of experienced surgeons, limited theater space, and awaiting radiological investigations (117).

A larger survey in 2010 showed that 58\% of surgeons performed index cholecystectomy for gallstone pancreatitis, but only $20 \%$ did for acute cholecystitis. Upper gastrointestinal and hepato-pancreato-biliary surgeons had much higher rates of index admission cholecystectomies compared to general surgeons (37 vs. $13 \%$ ). Procedures were mostly performed in emergency theaters, followed by the earliest available elective list. Limiting factors to early operation were theater availability and imaging delays. The authors suggested that more early cholecystectomies could be done if performed by upper gastro-intestinal or hepato-pancreato-biliary surgeons, or those performing laparoscopic cholecystectomy regularly. They also proposed a 12-h waitlist theater that runs separately from CEPOD (118).

In addition to the above, AUGIS also identifies surgeon apprehension, uncertain use of bile duct imaging (e.g., MRCP) and low rates of operative cholangiography and laparoscopic bile duct clearance in the UK as causes for delays (43).

\section{PROPOSED WAYS OF REDUCING TIME TO CHOLECYSTECTOMY}

There are several ways we could reduce time to cholecystectomy.

Firstly, is by curtailing unnecessary MRCP use. One way this could be achieved is through stricter adherence to serological and ultrasound parameters, so that only higher-risk patients undergo MRCP. Secondly, we recommend that IOC be performed more routinely where appropriate, allowing patients to have cholecystectomy and bile duct analysis as one procedure. The benefit of this is threefold: it relieves pressure on MRCP services (which are not always widely available), reduces pre-operative investigatory delays, and can shorten length of stay $(46,119)$. Stricter MRCP use has also been shown to reduce cost $(120,121)$.

Pre-operative ERCP for removal of CBD stones can cause similar delays. Laparoscopic bile duct exploration or intraoperative ERCP alongside laparoscopic cholecystectomy are both viable alternatives (43) that are equally as successful as preoperative ERCP, with no significant difference in morbidity or mortality (45). As well as expediting cholecystectomy, this obviates an uncomfortable procedure, as patients will already be anesthetized for their cholecystectomy.

Another option would be to make pre-operative MRCP/ ERCP more available. Davies et al. (122) found that introducing a non-urgent upper GI endoscopy service at the weekend reduced length of inpatient stay without increased mortality. Resource leveling studies on ERCP have also proposed a half-day Saturday list (123).

Similarly, a "Surgeon of the week" model could be introduced, as trialed by Agrawal et al. (124). They rostered an on-call consultant 6-days a week, from 8 am to 8 pm, on a 10-week cycle. This resulted in more cholecystectomies being done on index admission, without increase in morbidity.

For surgeons with ongoing reservations on early cholecystectomy, further training could be provided to familiarize "hot" gallbladder operations. Mercer et al. (125), found that integrating a specialist upper gastrointestinal surgical team (with 2 full-time and 2 part-time consultants) led to more acute cholecystectomies (67.3\% from 37.3\%), fewer readmissions, generally lower conversion rates and shorter hospital stay.

A final suggestion would be to alter how we prioritize theater spaces. The story of patients' cholecystectomies being intended for index admission and then being canceled and postponed is all too common. One solution could be to have dedicated acute cholecystectomy theater lists, either in addition to or in lieu of some elective lists. Alternatively, a separate "urgent" operating theater could run alongside the CEPOD list, so that fewer patients' procedures are canceled for emergencies. A South-East Wales study calculated that to treat 787 cholecystitis patients on index admission, there would need to be 12 cholecystectomies per week, across 5.4 operating sessions (126). Whilst NHS resource availability may not allow for this many weekly sessions, even having two sessions per week would help. If a morning list was done on a Monday and a Thursday, then the maximum a patient would have to wait for an index procedure would be $96 \mathrm{~h}$ (presuming there were no additional opportunistic spaces on other theater lists).

\section{DISCUSSION}

There were a few discussion points for this review. Firstly, not all studies had the same definitions for "late" or "early" cholecystectomy. For instance, some studies specified "late" as $>6$ weeks post initial presentation, for others it was $>7$ days. "Early" meant $<72 \mathrm{~h}$ for some researchers, $<96 \mathrm{~h}$ for others, and $<7$ days for a remainder. There therefore was likely to be some crossover between "late" and "early" groups between some studies, although the unanimous finding remains that "early" is safer and cheaper, regardless of differences in time criteria.

Secondly, many of the studies discussed were conducted at large tertiary care centers. Cameron and Goodman (127) examined gallstone pancreatitis outcomes in a UK district general hospital (DGH) and deemed early laparoscopic cholecystectomy "safe and feasible" without increased surgical difficulty. However, others have discussed a potential lack of sufficiently trained surgeons for early cholecystectomies in the DGH setting (126).

A final point to note is that much of the literature is focused toward cholecystectomy in the context of acute cholecystitis. Further research into cholecystectomy for other 
biliary pathologies might be useful; initial papers do highlight promising results.

\section{CONCLUSION}

Gallstone disease accounts for a large proportion of general surgical admissions. Early laparoscopic cholecystectomy has been shown to be safe with reduced rates of bile leak, morbidity and complications, shorter inpatient stay, and huge financial savings for hospital trusts and NHS as a whole. Performing the procedure early also greatly benefits the individual, with better quality of life, fewer days off work and reduced re-admission to hospital.

\section{REFERENCES}

1. Kang JY, Ellis C, Majeed A, Hoare J, Tinto A, Williamson RC, et al. Gallstones - an increasing problem: a study of hospital admissions in England between 1989/1990 and 1999/2000. Aliment Pharmacol Ther. (2003) 17:5619. doi: 10.1046/j.1365-2036.2003.01439.x

2. Russo MW, Wei JT, Thiny MT, Gangarosa LM, Brown A, Ringel Y, et al. Digestive and liver diseases statistics, 2004. Gastroenterology. (2004) 126:1448-53. doi: 10.1053/j.gastro.2004.01.025

3. Cao AM, Eslick GD. Epidemiology and pathogenesis of gallstones. In The Management of Gallstone Disease. Sydney, NSW: Springer International Publishing (2018). p. 53-66. doi: 10.1007/978-3-319-63884-3_3

4. Shaffer EA. Epidemiology of gallbladder stone disease. Best Pract Res Clin Gastroenterol. (2006) 20:981-96. doi: 10.1016/j.bpg.2006.05.004

5. Lammert F, Gurusamy K, Ko CW, Miquel JF, Méndez-Sánchez N, Portincasa P, et al. Gallstones. Nat Rev Dis Primers. (2016) 2:16024. doi: 10.1038/nrdp.2016.24

6. Gracie WA, Ransohoff DF. The natural history of silent gallstones: the innocent gallstone is not a myth. N Engl J Med. (1982) 307:798-800. doi: 10.1056/NEJM198209233071305

7. Gallstones - Complications - NHS. Available online at: https://www.nhs.uk/ conditions/gallstones/complications/ (accessed May 6, 2020).

8. Diehl AK. Gallstone Size and the Risk of Gallbladder Cancer. JAMA. (1983) 250:2323-6. doi: 10.1001/jama.1983.03340170049027

9. Lowenfels AB, Walker AM, Althaus DP, Townsend G, Domellöf L. Gallstone growth, size, and risk of gallbladder cancer: an interracial study. Int $J$ Epidemiol. (1989) 18:50-4. doi: 10.1093/ije/18.1.50

10. Nuño-Guzmán CM, Marín-Contreras ME, Figueroa-Sánchez M, Corona JL. Gallstone ileus, clinical presentation, diagnostic and treatment approach. World J Gastrointest Surg. (2016) 8:65. doi: 10.4240/wjgs.v8.i1.65

11. Glasgow RE, Cho M, Hutter MM, Mulvihill SJ, Pickleman J. The spectrum and cost of complicated gallstone disease in California. Arch Surg. (2000) 135:1021-7. doi: 10.1001/archsurg.135.9.1021

12. Pedrosa I, Guarise A, Goldsmith J, Procacci C, Rofsky NM. The interrupted rim sign in acute cholecystitis: a method to identify the gangrenous form with MRI. J Magnetic Resonance Imag. (2003) 18:360-3. doi: 10.1002/jmri.10356

13. Bourikian S, Anand RJ, Aboutanos M, Wolfe LG, Ferrada P. Risk factors for acute gangrenous cholecystitis in emergency general surgery patients. Am J Surg. (2015) 210:730-3. doi: 10.1016/j.amjsurg.2015.05.003

14. Wu $\mathrm{CH}$, Chen CC, Wang CJ, Wong YC, Wang LJ, Huang CC, et al. Discrimination of gangrenous from uncomplicated acute cholecystitis: accuracy of CT findings. Abdom Imaging. (2011) 36:174-8. doi: $10.1007 / \mathrm{s} 00261-010-9612-\mathrm{x}$

15. Bennett GL, Rusinek H, Lisi V, Israel GM, Krinsky GA, Slywotzky CM, et al. CT findings in acute gangrenous cholecystitis. Am J Roentgenol. (2002) 178:275-81. doi: 10.2214/ajr.178.2.1780275

16. Modini C, Clementi I, Simonelli L, Antoniozzi A, Assenza M, Ciccarone F, et al. Acute emphysematous cholecystitis as a cause of pneumoperitoneum. Chir Ital. (2008) 60:315-8. doi: 10.3748/wjg.v19.i4.604
Services should change to reflect this, but obstacles such as imaging delays and changeable operating theater slots persist. We have proposed several ways to overcome these, but they require a systemic and NHS-wide change in approach. If achieved, significant improvements in patient care can be made.

\section{AUTHOR CONTRIBUTIONS}

The authors state equal contribution in the preparation of this manuscript. All authors were involved in writing the article and preparing for submission.

17. Carrascosa MF, Salcines-Caviedes JR. Emphysematous cholecystitis. CMAJ. (2012) 184:E81. doi: 10.1503/cmaj.110601

18. Parekh J, Corvera CU. Hemorrhagic cholecystitis. Arch Surg. (2010) 145:2024. doi: 10.1001/archsurg.2009.265

19. Konno K, Ishida H, Naganuma H, Sato M, Komatsuda T, Sato A, et al. Emphysematous cholecystitis: Sonographic findings. Abdom Imaging. (2002) 27:191-5. doi: 10.1007/s00261-001-0054-3

20. Sunnapwar A, Raut AA, Nagar AM, Katre R. Emphysematous cholecystitis: imaging findings in nine patients. Indian J Radiol Imag. (2011) 21:142-6. doi: 10.4103/0971-3026.82300

21. Chawla A, Bosco JI, Lim TC, Srinivasan S, Teh HS, Shenoy JN. Imaging of acute cholecystitis and cholecystitis-associated complications in the emergency setting. Singapore Med J. (2015) 56:438-44. doi: 10.11622/smedj.2015120

22. Safioleas M, Stamatakos M, Safioleas P, Smyrnis A, Revenas C, Safioleas C. Mirizzi syndrome: an unexpected problem of cholelithiasis. Our experience with 27 cases. Int Semin Surg Oncol. (2008) 5:12. doi: 10.1186/1477-7800-5-12

23. Lee SK, Lee SC, Park JW, Kim SJ. The utility of the preoperative neutrophilTolymphocyte ratio in predicting severe cholecystitis: a retrospective cohort study. BMC Surg. (2014) 14:100. doi: 10.1186/1471-2482-14-100

24. Paulson EK. Acute cholecystitis: CT findings. Semin Ultrasound CT MRI. (2000) 21:56-63. doi: 10.1016/S0887-2171(00)90013-1

25. Yeh DD, Cropano C, Fagenholz P, King DR, Chang Y, Klein EN, et al. Gangrenous cholecystitis: deceiving ultrasounds, significant delay in surgical consult, and increased postoperative morbidity! J Trauma Acute Care Surg. (2015) 79:812-6. doi: 10.1097/TA.0000000000000832

26. Mayumi T, Okamoto K, Takada T, Strasberg SM, Solomkin JS, Schlossberg D, et al. Tokyo Guidelines 2018: management bundles for acute cholangitis and cholecystitis. J Hepatobiliary Pancreat Sci. (2018) 25:96-100. doi: $10.1002 /$ jhbp. 519

27. Miura F, Okamoto K, Takada T, Strasberg SM, Asbun HJ, Pitt HA, et al. Tokyo Guidelines 2018: initial management of acute biliary infection and flowchart for acute cholangitis. J Hepatobiliary Pancreat Sci. (2018) 25:31-40. doi: $10.1002 /$ jhbp. 509

28. Kiriyama S, Kozaka K, Takada T, Strasberg SM, Pitt HA, Gabata T, et al. (2018). Tokyo Guidelines 2018: diagnostic criteria and severity grading of acute cholangitis (with videos). J Hepatobiliary Pancreat Sci. 25:17-30. doi: $10.1002 /$ jhbp. 512

29. Peng WK, Sheikh Z, Paterson-Brown S, Nixon SJ. Role of liver function tests in predicting common bile duct stones in acute calculous cholecystitis. British J Surg. (2005) 92:1241-7. doi: 10.1002/bjs.4955

30. Yokoe M, Hata J, Takada T, Strasberg SM, Asbun HJ, Wakabayashi G, et al. Tokyo Guidelines 2018: diagnostic criteria and severity grading of acute cholecystitis (with videos). J Hepatobiliary Pancreat Sci. (2018) 25:41-54. doi: 10.1002/jhbp.515

31. Ahmed M, Diggory R. The correlation between ultrasonography and histology in the search for gallstones. Ann Royal Coll Surg Engl. (2011) 93:81-3. doi: 10.1308/003588411X12851639107070 
32. Elwood DR. Cholecystitis. Surg Clin North Am. (2008) 88:1241-52. doi: 10.1016/j.suc.2008.07.008

33. Bortoff GA, Chen MYM, Ott DJ, Wolfman NT, Routh WD. Gallbladder stones: Imaging and intervention. Radiographics. (2000) 20:751-66. doi: 10.1148/radiographics.20.3.g00ma16751

34. Cremer A, Arvanitakis M. Diagnosis and management of bile stone disease and its complications. Minerva Gastroenterol Dietol. (2016) 62:103-29.

35. Ralls PW, Colletti PM, Lapin SA, Chandrasoma P, Boswell WD, Ngo C, et al. Real-time sonography in suspected acute cholecystitis. Prospective evaluation of primary and secondary signs. Radiology. (1985) 155:767-71. doi: 10.1148/radiology.155.3.3890007

36. Revzin MV, Scoutt LM, Garner JG, Moore CL. Right upper quadrant pain: ultrasound first! J Ultrasound Med. (2017) 36:1975-85. doi: 10.1002/jum.14274

37. Bennett GL, Balthazar EJ. Ultrasound and CT evaluation of emergent gallbladder pathology. Radiol Clin North Am. (2003) 41:1203-16. doi: 10.1016/S0033-8389(03)00097-6

38. Menu Y, Vuillerme MP. Non-traumatic abdominal emergencies: Imaging and intervention in acute biliary conditions. In: Marincek B, Dondelinger RF, editors. Emergency Radiology - Imaging and Intervention. Berlin; Heidelberg: Springer (2007). p. 481-491.

39. Fazeli Dehkordy S, Wasnik AP, Cronin P. Acute Biliary Disorders in Adults: Evidence-Based Emergency Imaging of Acute Calculous and Acalculous Cholecystitis, Bile Duct Obstruction, and Choledocholithiasis. Cham: Springer. (2018). p. 309-327

40. Kiewiet JJ, Leeuwenburgh MM, Bipat S, Bossuyt PM, Stoker J, Boermeester MA. A systematic review and meta-analysis of diagnostic performance of imaging in acute cholecystitis. Radiology. (2012) 264:708-20. doi: 10.1148/radiol.12111561

41. Pinto A, Reginelli A, Cagini L, Coppolino F, Stabile Ianora AA, Bracale $\mathrm{R}$, et al. Accuracy of ultrasonography in the diagnosis of acute calculous cholecystitis: review of the literature. Crit Ultrasound J. (2013) 5:1-4. doi: 10.1186/2036-7902-5-S1-S11

42. Cholecystitis - acute - NICE CKS. Available online at: https://cks.nice.org.uk/ cholecystitis-acute\#!scenario (accessed December 12, 2019).

43. Beckingham I, Macutkiewicz C, Toogood, G, Maynard N. Pathway for the Management of Acute Gallstone Diseases. Association of Upper Gastrointestinal Surgery (2014). p. 1-12. Available online at: https://www. augis.org/wp-content/uploads/2014/05/Acute-Gallstones-Pathway-FinalSept-2015.pdf

44. Neugebauer EA, Becker M, Buess GF, Cuschieri A, Dauben HP, Fingerhut A, et al. EAES recommendations on methodology of innovation management in endoscopic surgery. Surg Endosc. (2010) 24:1594-615. doi: 10.1007/s00464-009-0818-3

45. Ansaloni, L, Pisanio M, Coccolini F, Peitzmann AB, Fingerhut A, Catena F, et al. WSES guidelines on acute calculous cholecystitis. World J Emerg Surg. (2016) 11:25. doi: 10.1186/s13017-016-0082-5

46. Buxbaum JL, Abbas Fehmi SM, Sultan S, Fishman DS, Qumseya BJ, et al. ASGE guideline on the role of endoscopy in the evaluation and management of choledocholithiasis Prepared by: ASGE STANDARDS OF PRACTICE COMMITTEE. Gastrointest endosc. (2019) 89:1075-105. doi: 10.1016/j.gie.2018.10.001

47. Quality statement 2: Urgent endoscopic retrograde cholangiopancreatography within 72 hours | Gallstone disease | Quality standards | NICE. Available online at: https://www.nice.org.uk/guidance/ qs104/chapter/Quality-statement-2-Urgent-endoscopic-retrogradecholangiopancreatography-within-72-hours (accessed December 15, 2019).

48. Recommendations | Gallstone disease: diagnosis and management | Guidance | NICE. Available online at: https://www.nice.org.uk/guidance/ cg188/chapter/recommendations\#diagnosing-gallstone-disease (accessed December 18, 2019).

49. Behari A, Kapoor VK. Asymptomatic Gallstones (AsGS) - To Treat or Not to? Indian J Surg. (2012) 74:4-12. doi: 10.1007/s12262-011-0376-5

50. Bingener J, Richards ML, Schwesinger WH, Strodel WE, Sirinek KR. Laparoscopic cholecystectomy for elderly patients: gold standard for golden years? Arch Surg. (2003) 138:531-5. doi: 10.1001/archsurg. 138.5.531
51. Portincasa P, Ciaula AD, Bonfrate L, Wang DQ. Therapy of gallstone disease: what it was, what it is, what it will be. World J Gastrointest Pharmacol Ther. (2012) 3:7-20. doi: 10.4292/wjgpt.v3.i2.7

52. Wiggins T, Markar SR, MacKenzie H, Faiz O, Mukherjee D, Khoo DE, et al. Optimum timing of emergency cholecystectomy for acute cholecystitis in England: population-based cohort study. Surg Endosc. (2019) 33:2495-502. doi: 10.1007/s00464-018-6537-x

53. Polo M, Duclos A, Polazzi S, Payet C, Lifante JC, Cotte E, et al. Acute cholecystitis-optimal timing for early cholecystectomy: a french nationwide study. J Gastrointest Surg. (2015) 19:2003-10. doi: 10.1007/s11605-015-2909-x

54. Zhu B, Zhang Z, Wang Y, Gong K, Lu Y, Zhang N. Comparison of laparoscopic cholecystectomy for acute cholecystitis within and beyond $72 \mathrm{~h}$ of symptom onset during emergency admissions. World J Surg. (2012) 36:2654-8. doi: 10.1007/s00268-012-1709-7

55. National Institute for Health and Care Excellence. Costing Statement: Gallstone Disease Implementing the NICE Guideline on Gallstone Disease (CG188). NICE (2014). Available online at: https://www.nice.org.uk/ guidance/cg188/resources/costing-statement-pdf-193298365 (accessed December 12, 2019).

56. David GG, Al-Sarira AA, Willmott S, Deakin M, Corless DJ, Slavin JP. Management of acute gallbladder disease in England. Br J Surg. (2008) 95:472-6. doi: 10.1002/bjs.5984

57. Murray AC, Markar S, Mackenzie H, Baser O, Wiggins T, Askari A, et al. An observational study of the timing of surgery, use of laparoscopy and outcomes for acute cholecystitis in the USA and UK. Surg Endosc. (2018) 32:3055-63. doi: 10.1007/s00464-017-6016-9

58. Koo KP, Thirlby RC. Laparoscopic cholecystectomy in acute cholecystitis: What is the optimal timing for operation? Arch Surg. (1996) 131:540-5. doi: 10.1001/archsurg.1996.01430170086016

59. Graves HA, Ballinger JF, Anderson WJ. Appraisal of laparoscopic cholecystectomy. Ann Surg. (1991) 213:655-64. doi: 10.1097/00000658-199106000-00017

60. Yamashita Y, Takada T, Kawarada Y, Nimura Y, Hirota M, Miura F, et al. Surgical treatment of patients with acute cholecystitis: Tokyo guidelines. $J$ Hepatobiliary Pancreat Sci. (2007) 14:91-7. doi: 10.1007/s00534-006-1161-x

61. Verma S, Agarwal PN, Bali RS, Singh, R, Talwar N. Early versus delayed laparoscopic cholecystectomy for acute cholecystitis: a prospective randomized trial. ISRN Minimally Invasive Surg. (2013) 2013:1-3. doi: $10.1155 / 2013 / 486107$

62. Papi C, Catarci MD, Ambrosio L, Gili L, Koch M, et al. Timing of cholecystectomy for acute calculous cholecystitis: a meta-analysis. Am J Gastroenterol. (2004) 99:147-55. doi: 10.1046/j.1572-0241.2003.04002.x

63. Casillas RA, Yegiyants, S, Collins JC. Early laparoscopic cholecystectomy is the preferred management of acute cholecystitis. Arch Surg. (2008) 143:5337. doi: 10.1001/archsurg.143.6.533

64. Cao AM, Eslick GD, Cox MR. Early cholecystectomy is superior to delayed cholecystectomy for acute cholecystitis: a meta-analysis. J Gastrointest Surg. (2015) 19:848-57. doi: 10.1007/s11605-015-2747-x

65. Hadad SM, Vaidya JS, Baker L, Koh HC, Heron TP, Hussain K, et al. Delay from symptom onset increases the conversion rate in laparoscopic cholecystectomy for acute cholecystitis. World J Surg. (2007) 31:1298-301. doi: 10.1007/s00268-007-9050-2

66. González-Rodríguez FJ, Paredes-Cotore JP, Ponton C, Rojo Y, Flores E, Luis-Calo ES, et al. Early or delayed laparoscopic cholecystectomy in acute cholecystitis? Conclusions of a controlled trial. Hepatogastroenterology. (2009) 56:11-6.

67. Kitano S, Matsumoto T, Aramaki M, Kawano K. Laparoscopic cholecystectomy for acute cholecystitis. J Hepatobiliary Pancreat Surg. (2002) 9:534-7. doi: 10.1007/s005340200069

68. Sreedhara AM. A comparative study of early versus delayed laparoscopic cholecystectomy for acute cholecystitis. IOSR J Dental Med Sci. (2018) 17:77-9. doi: 10.9790/0853-1710057779

69. Cull JD, Velasco JM, Czubak A, Rice D, Brown EC. Management of acute cholecystitis: prevalence of percutaneous cholecystostomy and delayed cholecystectomy in the elderly. J Gastrointest Surg. (2014) 18:328-33. doi: $10.1007 / \mathrm{s} 11605-013-2341-\mathrm{z}$ 
70. Abood RS, Huss AA, Handoz E. Early experience of laparoscopic cholecystectomy in the acutely inflamed gallbladder. J Pharmaceutical Sci Res. (2018) 10:2674-6.

71. Lo CM, Liu CL, Fan ST, Lai ECS, Wong J. Prospective randomized study of early versus delayed laparoscopic cholecystectomy for acute cholecystitis. Ann Surg. (1998) 227:461-7. doi: 10.1097/00000658-199804000-00001

72. Pessaux P, Tuech JJ, Rouge C, Duplessis R, Cervi C, Arnaud JP. Laparoscopic cholecystectomy in acute cholecystitis: a prospective comparative study in patients with acute vs chronic cholecystitis. Surg Endosc. (2000) 14:358-61. doi: $10.1007 / \mathrm{s} 004640020088$

73. Peng WK, Sheikh Z, Nixon SJ, Paterson-Brown S. Role of laparoscopic cholecystectomy in the early management of acute gallbladder disease. $\mathrm{Br}$ J Surg. (2005) 92:586-91. doi: 10.1002/bjs.4831

74. de Mestral C, Rotstein OD, Laupacis A, Hoch JS, Zagorski B, Alali AS, et al. Comparative operative outcomes of early and delayed cholecystectomy for acute cholecystitis: a population-based propensity score analysis. Ann Surg. (2014) 259:10-5. doi: 10.1097/SLA.0b013e3182a5cf36

75. Altieri MS, Brunt LM, Yang J, Zhu C, Talamini MA, Pryor AD. Early cholecystectomy $(<72 \mathrm{~h})$ is associated with lower rate of complications and bile duct injury: a study of 109,862 cholecystectomies in the state of New York. Surg Endosc. (2019) 34:3051-6. doi: 10.1007/s00464-019-07049-6

76. Gurusamy K, Samraj K, Gluud C, Wilson, E, Davidson BR. Meta-analysis of randomized controlled trials on the safety and effectiveness of early versus delayed laparoscopic cholecystectomy for acute cholecystitis. $\mathrm{Br} J$ Surg. (2010) 97:141-50. doi: 10.1002/bjs.6870

77. Contini S, Corradi D, Busi N, Alessandri L, Pezzarossa A, Scarpignato C. Can gangrenous cholecystitis be prevented? J Clin Gastroenterol. (2004) 38:710-6. doi: 10.1097/01.mcg.0000135898.68155.88

78. Escartín A, González M, Pinillos A, Cuello E, Muriel P, Tur J, et al. Failure to perform index cholecystectomy during acute cholecystitis results in significant morbidity for patients who present with recurrence. HPB. (2019) 21:876-82. doi: 10.1016/j.hpb.2018.11.007

79. Discolo A, Reiter S, French B, Hayes D, Lucas G, Tan L, et al. Outcomes following early versus delayed cholecystectomy performed for acute cholangitis. Surg Endosc. (2019) 34:3204-10. doi: 10.1007/s00464-019-07095-0

80. Nebiker CA, Frey DM, Hamel CT, Oertli D, Kettelhack C. Early versus delayed cholecystectomy in patients with biliary acute pancreatitis. Surgery. (2009) 145:260-4. doi: 10.1016/j.surg.2008.10.012

81. Singhal T, Balakrishnan S, Grandy-Smith S, Hunt J, Asante M, El-Hasani S. Gallstones: best served hot. JSLS. (2006) 10:332-5.

82. Cheruvu CVN, Eyre-Brook IA. Consequences of prolonged wait before gallbladder surgery. Ann Royal Coll Surg Engl. (2002) 84:20-2.

83. Somasekar K, Shankar PJ, Foster ME, Lewis MH. Costs of waiting for gall bladder surgery. Postgraduate Med J. (2002) 78:668-70. doi: $10.1136 / \mathrm{pmj} .78 .925 .668$

84. Lau H, Lo CY, Patil NG, Yuen WK. Early versus delayed-interval laparoscopic cholecystectomy for acute cholecystitis: a metaanalysis. Surg Endosc. (2006) 20:82-7. doi: 10.1007/s00464-006-0230-1

85. Johansson M, Thune A, Blomqvist A, Nelvin L, Lundell L. Management of acute cholecystitis in the laparoscopic era: results of a prospective, randomized clinical trial. J Gastrointest Surg. (2003) 7:642-5. doi: 10.1016/S1091-255X(03)00065-9

86. van Baal MC, Besselink MG, Bakker OJ, van Santvoort HC, Schaapherder AF, Nieuwenhuijs VB, et al. Timing of cholecystectomy after mild biliary pancreatitis. Ann Surg. (2012) 255:860-6. doi: 10.1097/SLA.0b013e3182507646

87. Sobolev B, Mercer D, Brown P, FitzGerald M, Jalink D, Shaw R. Risk of emergency admission while awaiting elective cholecystectomy. CMAJ. (2003) 169:662-5.

88. Jones C, Mawhinney A, Brown R. The true cost of gallstone disease. Ulster Med J. (2012) 81:10-3.

89. Wu XD, Tian X, Liu MM, Wu L, Zhao S, Zhao L. Meta-analysis comparing early versus delayed laparoscopic cholecystectomy for acute cholecystitis. $\mathrm{Br}$ J Surg. (2015) 102:1302-13. doi: 10.1002/bjs.9886

90. Minutolo V, Licciardello A, Arena M, Nicosia A, Di Stefano B, Calì G, et al. Laparoscopic cholecystectomy in the treatment of acute cholecystitis: comparison of outcomes and costs between early and delayed cholecystectomy. Eur Rev Med Pharmacol Sci. (2014) 18(2 Suppl):40-6.

91. Roulin D, Saadi A, di Mare L, Demartines, N. and Halkic N. (2016). Early Versus Delayed Cholecystectomy for Acute Cholecystitis, Are the 72 hours Still the Rule? Annals of Surgery 264, 717-722. doi: 10.1097/SLA.0000000000001886

92. Bhattacharya D, Senapati PSP, Hurle R, Ammori BJ. Urgent versus interval laparoscopic cholecystectomy for acute cholecystitis: a comparative study. $J$ Hepatobiliary Pancreat Surg. (2002) 9:538-42. doi: 10.1007/s005340200070

93. Siddiqui T, MacDonald A, Chong PS, Jenkins JT. Early versus delayed laparoscopic cholecystectomy for acute cholecystitis: a metaanalysis of randomized clinical trials. Am J Surg. (2008) 195:40-7. doi: 10.1016/j.amjsurg.2007.03.004

94. Rather ZM, Majid NA, Islam MN, Mohd RW. Outcome of early laparoscopic cholecystectomy versus delayed laparoscopic cholecystectomy for patients with acute cholecystitis. Int Surg J. (2020) 7:1217. doi: 10.18203/2349-2902.isj20201399

95. Shikata S, Noguchi Y, Fukui T. Early versus delayed cholecystectomy for acute cholecystitis: a meta-analysis of randomized controlled trials. Surg Today. (2005) 35:553-60. doi: 10.1007/s00595-005-2998-3

96. Oudhoff JP, Timmermans DRM, Bijnen AB, van der Wal G. Waiting for elective general surgery: physical, psychological and social consequences. ANZ J Surg. (2004) 74:361-7. doi: 10.1111/j.1445-1433.2004.02998.x

97. Lindseth GN, Denny DL. Patients' experiences with cholecystitis and a cholecystectomy. Gastroenterol Nursing. (2014) 37:407-14. doi: 10.1097/SGA.0000000000000072

98. Gurusamy KS, Davidson C, Gluud C, Davidson BR. Early versus delayed laparoscopic cholecystectomy for people with acute cholecystitis. Cochrane Database Syst Rev. (2013) 30:CD005440. doi: 10.1002/14651858.CD005440.pub3

99. Wilson E, Gurusamy K, Gluud C, Davidson BR. Cost-utility and value-ofinformation analysis of early versus delayed laparoscopic cholecystectomy for acute cholecystitis. Br J Surg. (2010) 97:210-9. doi: 10.1002/bjs.6872

100. Kerwat D, Zargaran A, Bharamgoudar R, Arif N, Bello G, Sharma B, et al. Early laparoscopic cholecystectomy is more cost-effective than delayed laparoscopic cholecystectomy in the treatment of acute cholecystitis. Clinicoecon Outcomes Res. (2018) 10:119-25. doi: 10.2147/CEOR.S149924

101. Morris S, Gurusamy KS, Patel N, Davidson BR. Cost-effectiveness of early laparoscopic cholecystectomy for mild acute gallstone pancreatitis. Br J Surg. (2014) 101:828-35. doi: 10.1002/bjs.9501

102. /20 National Tariff Payment System: national prices and prices for emergency care services (2019). Available online at: https://improvement.nhs.uk/ resources/national-tariff (accessed March 5, 2020).

103. Everhart J. Digestive Diseases in the United States: Epidemiology and Impact. Washington, DC: DIANE Publishing (1994).

104. Everhart JE, Ruhl CE. Burden of digestive diseases in the united states part iii: liver, biliary tract, and pancreas. Gastroenterology. (2009) 136:1134-44. doi: 10.1053/j.gastro.2009.02.038

105. Gul R, Dar RA, Sheikh RA, Salroo NA, Matoo AR, Wani SH. Comparison of early and delayed laparoscopic cholecystectomy for acute cholecystitis: Experience from a single center. North Am J Med Sci. (2013) 5:414-8. doi: 10.4103/1947-2714.115783

106. Kolla SB, Aggarwal S, Kumar A, Kumar R, Chumber S, Parshad $\mathrm{R}$, et al. Early vs delayed laparoscopic cholecystectomy for acute cholecystitis: a prospective randomized trial. Surg Endosc. (2004) 18:1323-7. doi: 10.1007/s00464-003-9230-6

107. Kumar R, Singh Mahi S, Walia R, Goyal S. Comparison between early and delayed laparoscopic cholecystectomy in acute cholecystitis: a prospective study. MedPulse Int J Surg. (2019) 12:74-9. doi: 10.26611/1061231

108. Agrawal R, Sood KC, Agarwal B. Clinical study evaluation of early versus delayed laparoscopic cholecystectomy in acute cholecystitis. (2015) 2015:349801. doi: 10.1155/2015/349801

109. Norrby S, Herlin P, Holmin T, Sjödahl R, Tagesson C. Early or delayed cholecystectomy in acute cholecystitis? A clinical trial. Br J Surg. (1983) 70:163-5. doi: 10.1002/bjs.1800700309

110. Chang TC, Lin MT, Wu MH, Wang MY, Lee PH. Evaluation of early versus delayed laparoscopic cholecystectomy in the treatment of acute cholecystitis. Hepatogastroenterology. (2009) 56:26-8. 
111. Coccolini F, Catena F, Pisano M, Gheza F, Fagiuoli S, Di Saverio S, et al. Open versus laparoscopic cholecystectomy in acute cholecystitis. Systematic review and meta-analysis. Int J Surg. (2015) 18:196-204. doi: 10.1016/j.ijsu.2015.04.083

112. Chandler CF, Lane JS, Ferguson P, Thompson JE, Ashley SW. Prospective evaluation of early versus delayed laparoscopic cholecystectomy for treatment of acute cholecystitis. Am Surg. (2000) 66:896-900.

113. Okamoto K, Suzuki K, Takada T, Strasberg SM, Asbun HJ, Endo I, et al. Tokyo Guidelines 2018: flowchart for the management of acute cholecystitis. J Hepatobiliary Pancreat Sci. (2018) 25:55-72. doi: 10.1002/ jhbp. 516

114. Karakayali FY, Akdur A, Kirnap M, Harman A, Ekici Y, Moray G. Emergency cholecystectomy vs percutaneous cholecystostomy plus delayed cholecystectomy for patients with acute cholecystitis. Hepatobiliary Pancreat Dis Int. (2014) 13:316-22. doi: 10.1016/S1499-3872(14) 60045-X

115. El-Gendi A, El-Shafei M, Emara D. Emergency versus delayed cholecystectomy after percutaneous transhepatic gallbladder drainage in grade II acute cholecystitis patients. J Gastrointest Surg. (2017) 21:284-93. doi: 10.1007/s11605-016-3304-y

116. Blythe J, Herrmann E, Faust D, Falk S, Edwards-Lehr T, Stockhausen F, et al. (2018). Acute cholecystitis andndash; a cohort study in a real-world clinical setting (REWO study, NCT02796443). Pragmat Obs Res. 9:69-75. doi: $10.2147 /$ POR.S169255

117. Cameron IC, Chadwick C, Phillips J, Johnson AG, Cameron IC. Management of acute cholecystitis in UK hospitals: time for a change. Postgrad Med J. (2004) 80:292-4. doi: 10.1136/pgmj.2002. 004085

118. Senapati PSP, Bhattarcharya D, Harinath G, Ammori BJ. A survey of the timing and approach to the surgical management of cholelithiasis in patients with acute biliary pancreatitis and acute cholecystitis in the UK. Ann Royal Coll Surg Engl. (2003) 85:306-12. doi: 10.1308/003588403769 162404

119. Thacoor A, Pike TW, Pathak S, Dixon J, Macutkiewicz C, Smith AM. The role of intraoperative cholangiography in patients undergoing laparoscopic cholecystectomy for acute gallstone pancreatitis: Is magnetic resonance cholangiopancreatography needed? Ann Royal Coll Surg Engl. (2019) 101:428-31. doi: 10.1308/rcsann.2019.0049
120. Singhvi G, Ampara R, Baum, J, Gumaste V. ASGE guidelines result in cost-saving in the management of choledocholithiasis. Ann Gastroenterol. (2016) 29:85-90.

121. Isherwood J, Garcea G, Williams R, Metcalfe M, Dennison A. Serology and ultrasound for diagnosis of choledocholithiasis. Ann Royal Coll Surg Engl. (2014) 96:224-8. doi: 10.1308/003588414X13814021678033

122. Davies AHG, Ishaq S, Brind AM, Bowling TE, Green JRB. Availability of fully staffed GI endoscopy lists at the weekend for inpatients: Does it make a difference? [9]. Clin Med. (2003) 3:189-90. doi: 10.7861/clinmedicine.3-2-189a

123. Hendrick LM, Harewood GC, Patchett SE, Murray FE. Utilization of resource leveling to optimize ERCP efficiency. Irish J Med Sci. (2011) 180:143-8. doi: 10.1007/s11845-010-0570-7

124. Agrawal S, Battula N, Barraclough L, Durkin D, Cheruvu CVN. Early laparoscopic cholecystectomy service provision is feasible and safe in the current UK national health service. Ann Royal Coll Surg Engl. (2009) 91:6604. doi: 10.1308/003588409X464478

125. Mercer SJ, Knight JS, Toh SK, Walters AM, Sadek SA, Somers SS. Implementation of a specialist-led service for the management of acute gallstone disease. Br J Surg. (2004) 91:504-8. doi: 10.1002/bjs.4458

126. Stephens MR, Beaton C, Steger AC. Early cholecystectomy after acute admission with cholecystitis: how much work? World J Surg. (2010) 34:20414. doi: 10.1007/s00268-010-0606-1

127. Cameron DR, Goodman AJ. Delayed cholecystectomy for gallstone pancreatitis: re-admissions and outcomes. Ann Royal Coll Surg Engl. (2004) 86:358-62. doi: 10.1308/147870804227

Conflict of Interest: The authors declare that the research was conducted in the absence of any commercial or financial relationships that could be construed as a potential conflict of interest.

Copyright (C) 2020 Argiriov, Dani, Tsironis and Koizia. This is an open-access article distributed under the terms of the Creative Commons Attribution License (CC BY). The use, distribution or reproduction in other forums is permitted, provided the original author(s) and the copyright owner(s) are credited and that the original publication in this journal is cited, in accordance with accepted academic practice. No use, distribution or reproduction is permitted which does not comply with these terms. 